This document is confidential and is proprietary to the American Chemical Society and its authors. Do not copy or disclose without written permission. If you have received this item in error, notify the sender and delete all copies.

\title{
Organic covalent patterning of nanostructured graphene with selectivity at the atomic level
}

\begin{tabular}{|c|c|}
\hline Journal: & Nano Letters \\
\hline Manuscript ID & nl-2015-03928e.R1 \\
\hline Manuscript Type: & Communication \\
\hline Date Submitted by the Author: & $\mathrm{n} / \mathrm{a}$ \\
\hline Complete List of Authors: & $\begin{array}{l}\text { Navarro, Juan Jesús; IMDEA Nanociencia } \\
\text { Leret, Sofia; IMDEA Nanociencia } \\
\text { Calleja, Fabian; IMDEA Nanociencia } \\
\text { Stradi, Daniele; Instituto Madrileño de Estudios Avanzados en Nanociencia } \\
\text { (IMDEA Nanociencia); Universidad Autonoma de Madrid, Departamento de } \\
\text { Quimica Modulo13 } \\
\text { Black, Andrés; Universidad Autonoma de Madrid, Fisica de la Materia } \\
\text { Condensada; IMDEA Nanociencia } \\
\text { Bernardo-Gavito, Ramón; Universidad Autonoma de Madrid, Fisica de la } \\
\text { Materia Condensada; IMDEA Nanociencia } \\
\text { Garnica, Manuela; IMDEA Nanociencia; Universidad Autonoma de Madrid, } \\
\text { Fisica de la Materia Condensada } \\
\text { Granados, Daniel; IMDEA Nanociencia } \\
\text { Vazquez de Parga, Amadeo; Universidad Autonoma de Madrid, Fisica de la } \\
\text { Materia Condensada } \\
\text { Pérez, Emilio; IMDEA Nanoscience, } \\
\text { Miranda, Rodolfo; Universidad Autonoma de Madrid; IMDEA Nanociencia }\end{array}$ \\
\hline
\end{tabular}

\section{SCHOLARONE \\ Manuscripts}




\title{
Organic covalent patterning of nanostructured graphene with selectivity at the atomic level
}

\author{
Juan Jesús Navarro ${ }^{a}$, Sofía Leret ${ }^{a}$, Fabián Calleja $^{a}$, Daniele Stradi ${ }^{a, b,{ }^{\dagger}}$, Andrés Black ${ }^{a, c}$, Ramón \\ Bernardo-Gavito $^{a, c}$, Manuela Garnica ${ }^{a, c, t,}$, Daniel Granados ${ }^{a}$, Amadeo L. Vázquez de Parga ${ }^{a, c, *}$, \\ Emilio M. Pérez ${ }^{a,{ }^{*}}$, Rodolfo Miranda ${ }^{a, c}$. \\ ${ }^{a}$ IMDEA Nanociencia, Calle Faraday 9, Cantoblanco 28049, Madrid, Spain \\ b Departamento de Química, Módulo13, Universidad Autónoma de Madrid, Cantoblanco 28049, \\ Madrid, Spain \\ ${ }^{\mathrm{c}}$ Departamento de Física de la Materia Condensada and IFIMAC, Universidad Autónoma de \\ Madrid, Cantoblanco 28049, Madrid, Spain.
}

\begin{abstract}
Organic covalent functionalization of graphene with long-range periodicity is highly desirable -it is anticipated to provide control over its electronic, optical, or magnetic properties- and remarkably challenging. In this work we describe a method for the covalent modification of graphene with strict spatial periodicity at the nanometer scale. The periodic landscape is provided by a single monolayer of graphene grown on $\mathrm{Ru}(0001)$, that presents a moiré pattern due to the mismatch between the carbon and ruthenium hexagonal lattices. The moiré contains periodically arranged areas where the graphene-ruthenium interaction is enhanced and shows higher chemical reactivity. This phenomenon is demonstrated by the attachment of
\end{abstract}


cyanomethyl radicals $\left(\mathrm{CH}_{2} \mathrm{CN}^{*}\right)$ produced by homolytic breaking of acetonitrile $\left(\mathrm{CH}_{3} \mathrm{CN}\right)$, which is shown to present a nearly complete selectivity ( $>98 \%)$ to bind covalently to graphene on specific atomic sites. This method can be extended to other organic nitriles, paving the way for the attachment of functional molecules.

KEYWORDS: nanostructured graphene, epitaxial graphene, chemical functionalization, scanning tunneling microscopy 
Graphene is a bidimensional network of $\mathrm{sp}^{2}$-hybridized carbon atoms. The planar hexagonal arrangement of carbon in graphene, its chemical stability, and most significantly, its extraordinary physical properties all stem from the extended conjugation provided by the homogeneous $\mathrm{sp}^{2}$ hybridization. ${ }^{1}$ The chemical functionalization of graphene has been intensely pursued in the last years. ${ }^{2,3}$ A significant part of the research efforts from the wet chemistry trench have focused on the covalent attachment of molecular fragments to graphene. Addition of malonate-type carbanions and radicals, acylations, and a wide variety of cycloadditions, including [2+1], $[2+2],[3+2]$, and [4+2], have all been explored, among others. ${ }^{4-7}$ Negative consequences of graphene's planar geometry are its insolubility and its tendency to reaggregate to form graphite through $\pi-\pi$ and van der Waals interactions. Such issues can be solved using graphene on a suitable substrate (for a recent review see Criado et $\mathrm{al}^{8}{ }^{8}$ ). It has been demonstrated that graphene grown or deposited on a substrate can physisorb or chemisorb molecules. Weakly attached adsorbates can act as donors or acceptors leading to changes in carrier concentration that allow the detection of single molecules ${ }^{9}$ or the formation of intermolecular bands with long range magnetic order at low temperatures. ${ }^{10}$ Beyond the supramolecular functionalization of epitaxial graphene, its covalent modification has been proposed as an ideal tool for adjusting the electronic, optical or magnetic properties. The chemical oxidation of graphene in ultra-high vacuum (UHV) conditions has also been demonstrated. ${ }^{11,12}$ The attachment of hydrogen to each atomic site of the graphene lattice to create graphane was proposed, ${ }^{13}$ resulting in a change in the hybridization of carbon atoms from $\mathrm{sp}^{2}$ to $\mathrm{sp}^{3}$, as well as the opening a sizeable gap at the Dirac point. ${ }^{14-16}$ In these experiments, all the atoms in the graphene lattice exhibit very similar reactivity and the only way to get an atomically well-defined long range order is to saturate all the atomic sites, creating a completely new material, e.g. graphane or graphene oxide. This lack 
of selectivity is a major drawback if the objective of the covalent modification is to modulate the electronic properties of graphene. It has been predicted that a periodic patterning of graphene would lead to new electronic properties ${ }^{17}$ including a direct relation between the periodicity and the bandgap amplitude. ${ }^{18,19}$ Therefore the chemical functionalization of graphene in a periodic fashion with a periodicity in the range of 1 to $5 \mathrm{~nm}$ is highly desirable.

There have been several approaches for obtaining site selectivity in the chemical functionalization of graphene. One approach relies on patterning the surface using an atomic force microscope (AFM). ${ }^{20,21}$ The main drawback of this approach is the time needed to write the motifs and also the difficulty of scaling the process to millimetre size samples. Another approach relies on the fact that strain and curvature strongly enhance the local reactivity of the graphene, ${ }^{22,23}$ although so far no long range order has been achieved. Graphene grown on metallic substrates presents a moiré pattern due to the difference in lattice parameter between graphene and the substrate. ${ }^{24}$ In particular, graphene grown on $\operatorname{Ir}(111)$ has been used to study the influence of a spatially ordered covalent functionalization in the graphene electronic structure. $^{25,26}$ Due to the weak interaction between the graphene and the $\operatorname{Ir}(111)$ substrate, the moiré pattern presents several rotational domains with different periodicities. ${ }^{27,28}$ The weak interaction with the substrate also renders all the carbon atoms almost identical electronically and no distinct reactive sites are present in the system. To the best of our knowledge, there have been no reports of covalent functionalization of graphene with atomic-level selectivity.

Here, we describe a method for the organic covalent modification of graphene with exquisite spatial periodicity at the atomic scale. We take advantage of the fact that the growth of graphene on lattice-mismatched metallic substrates allows us to tailor the geometric and electronic properties of the graphene overlayer in a periodic fashion. In particular, we use graphene grown 
on $\mathrm{Ru}(0001)$ that presents a moiré pattern with a periodicity of $\approx 3 \mathrm{~nm}$. The moiré shows periodically distributed areas where the charge transfer due to the interaction between graphene and ruthenium is rather large and, as a consequence, these graphene areas present higher chemical reactivity. This point is illustrated by demonstrating that cyanomethyl radicals $\left(\mathrm{CH}_{2} \mathrm{CN}^{\bullet}\right)$ produced by homolytic breaking of acetonitrile $\left(\mathrm{CH}_{3} \mathrm{CN}\right)$ in $\mathrm{UHV}$ by electron bombardment bind to graphene preferentially at specific atomic sites with a nearly complete selectivity $(>98 \%)$.

Growth of graphene through chemical vapour deposition (CVD) on a variety of metallic substrates is one of the preferred methods for the synthesis of high-quality graphene. ${ }^{29-32}$ This method presents the additional advantage that the strength in the interaction between graphene and the metallic substrate can be tuned by varying the chemical nature of the latter. ${ }^{33}$ In this respect some of us have previously reported the epitaxial growth of graphene on $\mathrm{Ru}(0001)$ (hereafter, $\mathrm{gr} / \mathrm{Ru}(0001)$ ) where due to the mismatch between the hexagonal lattices of graphene and $\mathrm{Ru}$, the system presents a moiré pattern with a surface periodicity of $2.93 \mathrm{~nm}^{34}$ (see Supporting Information A for further details). Figure 1(a) shows that three different areas can be distinguished inside the moiré unit cell depending on the registry between the carbon atoms and the last two ruthenium atomic layers, namely: the "atop" region where all carbon atoms are placed above threefold hollow sites of the Ru surface (vertex of the blue triangles in Fig. 1(a)), the "HCP-Top" region where half of the carbon atoms are located on HCP threefold positions and the other half on top of Ru atoms (dashed blue triangle in Fig. 1(a)) and the "FCC-Top" region where half of the carbon atoms are located on FCC threefold positions and the other half on top of Ru atoms (solid blue triangle in Fig. 1(a)). 
(a)

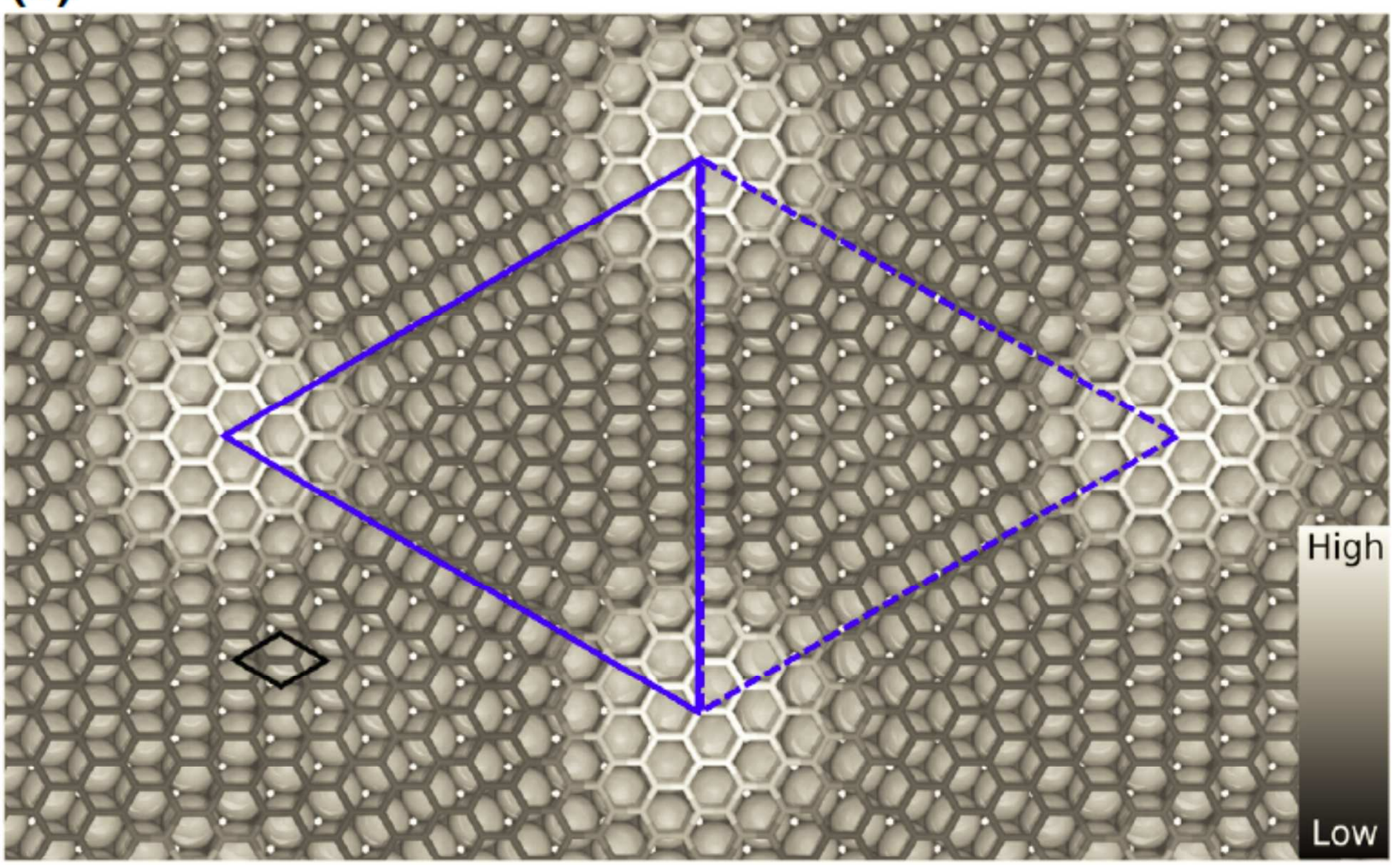

(b)

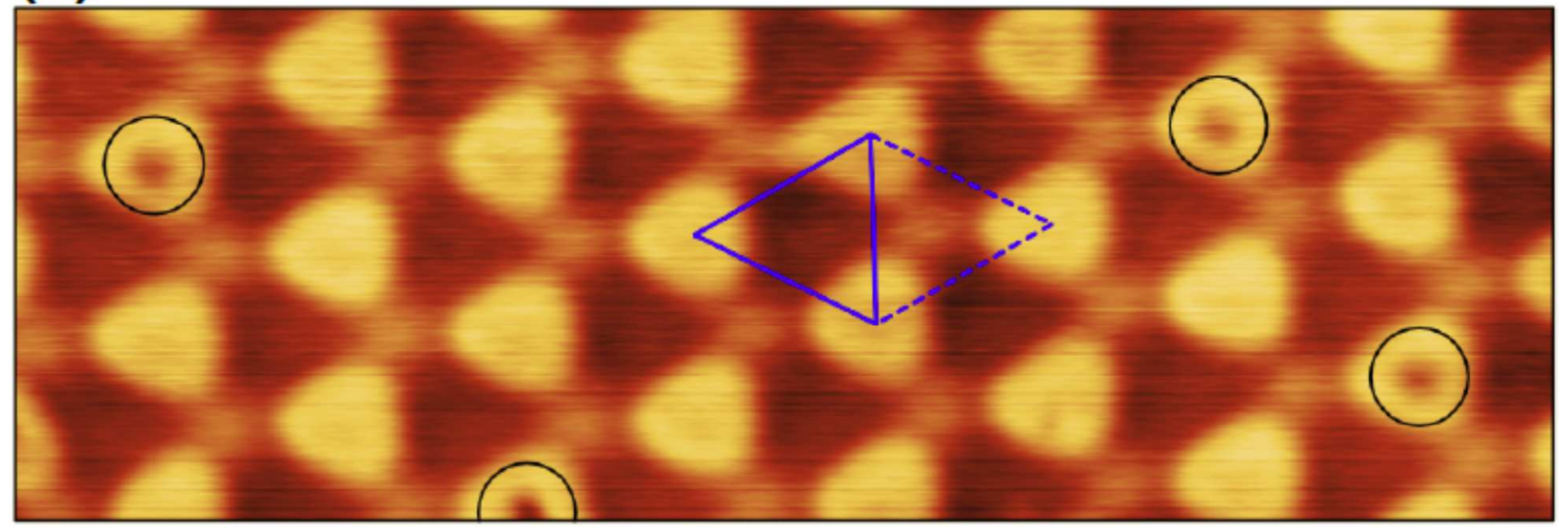

Figure 1. (a) Ball model of the $\mathrm{gr} / \mathrm{Ru}(0001)$ surface, where grey circles represent the $\mathrm{Ru}$ atoms of the first atomic layer. The graphene hexagonal lattice is shown in a black to white color scale to indicate the height of the carbon atoms respect to the $\mathrm{Ru}(0001)$ surface. The unit cell of the moiré pattern is highlighted by two blue triangles. At the vertices all carbon atoms fall on threefold hollow sites of the $\mathrm{Ru}(0001)$ surface. At the center of the solid (dashed) triangle one 
carbon sub-lattice falls on FCC-stacked (HCP-stacked) threefold hollow sites and the other one on top positions. These two regions are named "FCC-Top" and "HCP-Top" respectively. (b) STM image acquired on pristine $\mathrm{gr} / \mathrm{Ru}(0001)\left(24 \times 7 \mathrm{~nm}^{2} ; \mathrm{V}_{\mathrm{b}}=+1.5 \mathrm{~V}, \mathrm{I}_{\mathrm{t}}=30 \mathrm{pA}\right)$. The moiré pattern arising from the lattice mismatch is highlighted in blue. The HCP-Top area is marked with the dashed triangle and the FCC-Top area is marked the solid triangle. Four point defects on the atop areas are indicated by black circles.

Figure 1(b) shows a Scanning Tunneling Microscope (STM) topographic image of the surface measured at $+1.5 \mathrm{~V}$ bias voltage. Under these bias conditions, the moiré appears as a hexagonal array of bumps with a small corrugation $(\sim 40 \mathrm{pm})$. The origin of the bumps is the change in registry within the moiré unit cell that produces a spatial modulation in the interaction between the $\mathrm{C}$ and $\mathrm{Ru}$ atoms, from weak van der Waals interaction in the high areas of the STM images to strong interaction in the lower areas. ${ }^{35,36}$ This spatial variation of the interaction modulates all surface electronic properties, from the surface potential ${ }^{37}$ to the electronic structure around the Fermi level, ${ }^{34}$ which directly affects the chemical reactivity. The STM imaging conditions of Figure $1 \mathrm{~b}$ also reveal the presence of four point defects on top of the ripples (marked with black circles), which we attribute to subsurface oxygen trapped during the graphene growth process (see Supporting Information B for details).

Recently, Ruoff, Bielawsky and co-workers have introduced a method for the selective functionalization of graphene on areas with high local curvature. ${ }^{22}$ Considering this, and the seminal work by Balog et al. on the patterned hydrogenation of graphene on $\operatorname{Ir}^{25}$ we reasoned that graphene on $\mathrm{Ru}(0001)$ seems an ideal playground to exploit a similar strategy for a periodic chemical modification of graphene with sub-nanoscale selectivity. The metal-graphene interaction in $\mathrm{gr} / \mathrm{Ru}(0001)$ is sufficiently strong to affect the chemical reactivity of specific 
atomic sites of the graphene overlayer, due to the presence of the moiré-related corrugation. While attempting to reproduce the wet-chemistry reaction conditions, we serendipitously discovered that $\mathrm{gr} / \mathrm{Ru}(0001)$ can be functionalized by cyanomethyl radicals with exquisite spatial selectivity (see Supporting Information C for details). Representative STM images are shown in Figure $2 \mathrm{a}-\mathrm{f}$, measured at $80 \mathrm{~K}$ as a function of the sample bias voltage after exposure of the sample at room temperature to $1 \times 10^{-6}$ Torr of $\mathrm{CH}_{3} \mathrm{CN}$ for 3 minutes, equivalent to 180 Langmuirs. Bright bumps related to the adsorption of acetonitrile, located exclusively at the valleys and the HCP-top sites, are observed for voltages between $+1.25 \mathrm{~V}$ and $+2 \mathrm{~V}$. The molecular attachments show an apparent height of $26 \pm 2 \mathrm{pm}$ and a lateral width of $560 \pm 20 \mathrm{pm}$ at $+1.5 \mathrm{~V}$. The shape and size of the molecular attachments are very similar to those measured on STM images taken of acetonitrile adsorbed on $\mathrm{Pt}(111) .{ }^{38}$ Figure $2(\mathrm{~g})$ shows Scanning Tunnelling Spectroscopy (STS) recorded on various positions of the moiré unit cell. The curves measured on top of the ripples and the ones measured on the (empty) low areas of the moiré show the well-known asymmetry between the occupied and empty density of states of $\mathrm{gr} / \mathrm{Ru}(0001) .{ }^{34}$ The curves measured on the molecular attachments present an additional peak at $+1.6 \mathrm{eV}$ identified as the Lowest Unoccupied Molecular Orbital (LUMO). The energy of the Highest Occupied Molecular Orbital (HOMO) is below -2.0 V and, therefore, out of the measured energy window. The images confirm that for bias voltages below $+0.5 \mathrm{~V}$ the molecular attachments are not visible, since tunneling is being carried out in the gap between the HOMO and LUMO. For bias voltages larger than $+2.5 \mathrm{~V}$ the reduction in the apparent corrugation of the moiré pattern and its subsequent inversion ${ }^{39}$ hinders the precise identification of the adsorption site of the molecular attachments. 

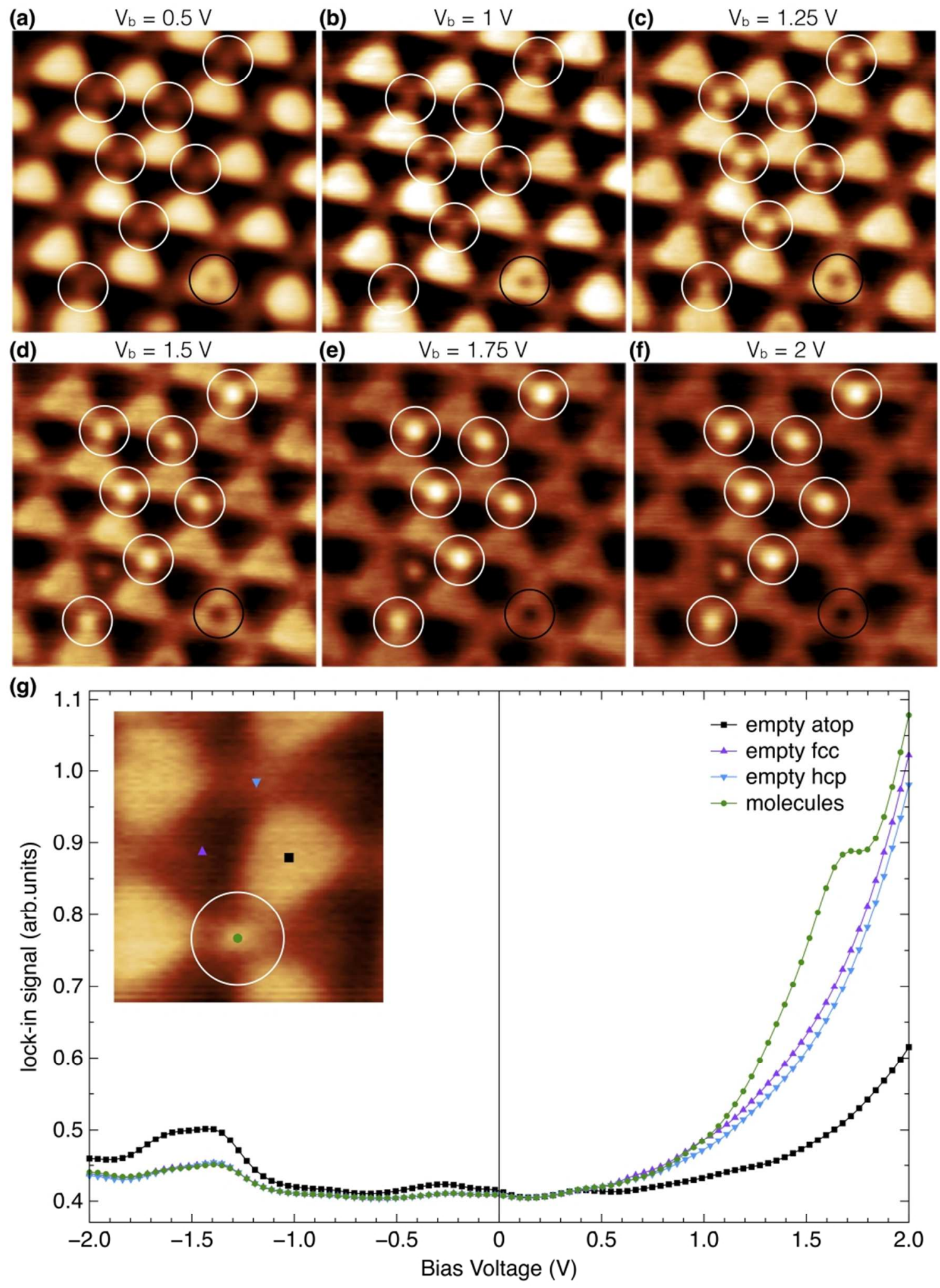

ACS Paragon Plus Environment 
Figure 2. (a)-(f) $10 \times 10 \mathrm{~nm}^{2} \mathrm{STM}$ images with different bias voltages acquired at $80 \mathrm{~K}$ after exposing $\mathrm{gr} / \mathrm{Ru}(0001)$ to 180 Langmuir of acetonitrile at $300 \mathrm{~K}$. Notice the related presence of seven bright bumps on HCP-Top sites (marked with a white circle), one on FCC-Top site and one graphene point defect (marked with a black circle). (g) Differential conductance, dI/dV, curves recorded at $80 \mathrm{~K}$ with the tip of the STM placed on top of the molecular attachments (green), the FCC-Top, HCP-Top (purple and blue, respectively) and the ripples (black) areas of the moiré pattern of $\mathrm{gr} / \mathrm{Ru}(0001)$. The $\mathrm{dI} / \mathrm{dV}$ individual curves were measured in open feedback loop conditions with the tunneling gap stabilized at $+0.3 \mathrm{~V}$ and $50 \mathrm{pA}$. The lock-in signal was acquired using a modulation in the bias voltage of $40 \mathrm{mV}(\mathrm{rms})$, a frequency of $856 \mathrm{~Hz}$ and a time constant of $10 \mathrm{~ms}$.

Remarkably, single molecular attachments can be observed exclusively at the valleys of the moiré pattern. Moreover, there is a strong preference for HCP-Top sites over FCC-top regions offering another level of selectivity. For higher coverages on the order of 0.50 acetonitrile molecules per moiré unit cell, $98.0 \pm 1 \%$ of the HCP-Top and $2 \pm 1 \%$ of the FCC-Top areas of the unit cells are occupied. The same site preference has been observed for $\mathrm{TCNQ}^{40}$ and $\mathrm{F} 4-\mathrm{TCNQ}^{41}$ molecules adsorbed on $\mathrm{gr} / \mathrm{Ru}(0001)$ and can be understood considering the difference in the electronic structure between the FCC-Top and HCP-Top areas. ${ }^{40}$

In the present case, however, the bonding between the adsorbed molecular attachments and graphene relies on a strong $\mathrm{C}-\mathrm{C}$ covalent bond, which modifies the $\mathrm{sp}^{2}$ hybridization of a single $\mathrm{C}$ atom in graphene. This is demonstrated in Figure 3, in which a region containing three molecular attachments located in HCP-Top regions, encircled in white, is imaged with atomic resolution. The STM image has been taken in conditions where the molecular attachment is transparent ( $2 \mathrm{mV}$ bias and $800 \mathrm{pA}$ current) because the small bias voltage is probing the energy 
gap between HOMO and LUMO of the adsorbed molecule. Accordingly, the tip does not move up when is located on top of the molecules attached to the surface. Simultaneously, the C atoms with a modified hybridization where the three molecules are bonded appear as single atom "holes" (see Supporting Information F.3 and Fig. S7 for details). Remarkably, the covalent attachments are located exclusively on crystallographically identical carbon atoms of the graphene overlayer. The inset shows the bright bumps of the molecules adsorbed in the "hole" sites by restoring a bias voltage where they can be imaged through their LUMO orbitals. In spite of the harsh imaging conditions all three molecules remain in place without any noticeable change in shape or position. Going down to atomic resolution parameters without sweeping the molecular attachments away during the scan is contrary to what happens with physisorbed or even strongly chemisorbed isolated molecules, such as $\mathrm{TCNQ}^{9}$ or $\mathrm{F}_{4}-\mathrm{TCNQ}^{42}$, indicating the covalent nature of their attachment to graphene. In fact, the molecular attachments cannot be displaced from their adsorption sites by the STM tip following standard manipulation techniques. $^{43,44}$ Annealing the sample in UHV further confirms the strong bond between graphene and the molecular attachments. The sample remains unaltered up to $573 \mathrm{~K}$. 


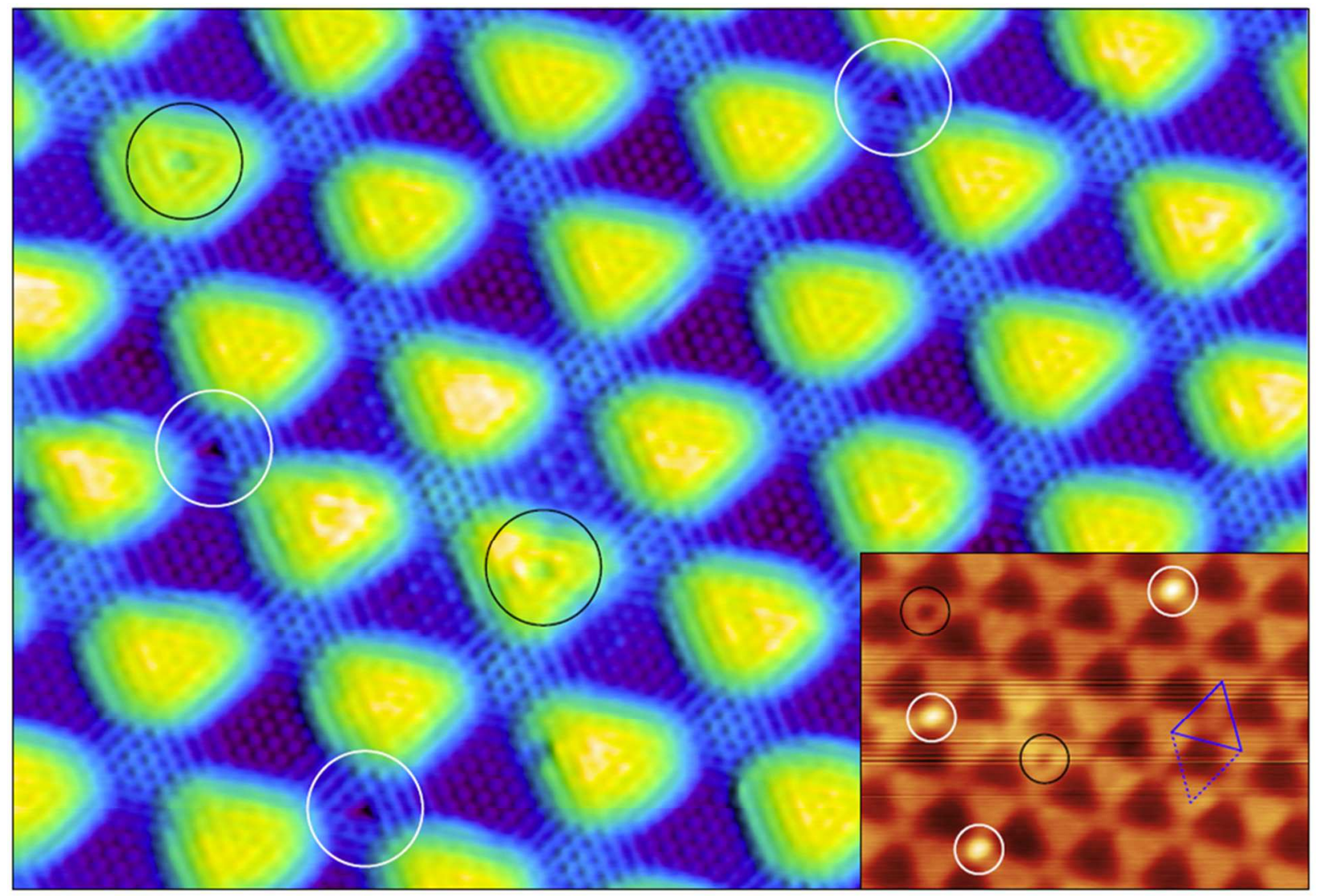

Figure 3. High resolution STM image $\left(17 \times 12 \mathrm{~nm}^{2}, \mathrm{~V}_{\mathrm{b}}=2 \mathrm{mV}, \mathrm{I}_{\mathrm{t}}=800 \mathrm{pA}\right)$, acquired at $80 \mathrm{~K}$ on a region containing three molecular species (white circles) and two oxygen-related defects on graphene (black circles). Inset: Same region scanned afterwards with $V_{b}=+1.7 \mathrm{~V}$ and $I_{t}=100$ pA. All three molecular attachments are still in place. The moiré unit cell is highlighted in blue in the inset.

These facts confirm the selective covalent patterning of $\mathrm{gr} / \mathrm{Ru}(0001)$ through treatment with $\mathrm{CH}_{3} \mathrm{CN}$ beyond reasonable doubt. Given the relatively inert nature of $\mathrm{CH}_{3} \mathrm{CN}$, and knowing that under high-vacuum ( $10^{-6}$ Torr) conditions ion gauges produce and emit active chemical species through ionization of the residual gases in the vacuum chamber, which can be adsorbed onto graphene,${ }^{45}$ we reasoned the same process may take place during the exposure of the graphene surface to the acetonitrile molecules in UHV, since we use an ion gauge to measure the partial 
pressure of the acetonitrile gas. In order to gather experimental evidence of the molecular fragments that can be produced in the ion gauge during the $\mathrm{CH}_{3} \mathrm{CN}$ exposition, we introduced in the UHV chamber the same partial pressure $\left(1 \times 10^{-6}\right.$ Torr $)$ of acetonitrile used during the graphene exposure and recorded the mass spectrum of the gas utilizing a quadrupole mass spectrometer (QMS) (see Supporting Information D for details). The ionization chamber of the QMS works under the same physical principle as the ion gauges and therefore the spectra measured is a reliable indicator of the chemical species produced in the ion gauge. The $\mathrm{m} / \mathrm{z}$ pattern is perfectly consistent with a significant concentration of $\mathrm{CH}_{2} \mathrm{CN}^{\bullet}$ (Figure $\mathrm{S} 3$ and Supporting Information D for details). It is well known that $\mathrm{CH}_{2} \mathrm{CN}^{\bullet}$ can be generated directly from $\mathrm{CH}_{3} \mathrm{CN}$ by homolytic cleavage of a C-H bond. ${ }^{46-48}$ Moreover, the cyanomethyl radical $\left(\mathrm{CH}_{2} \mathrm{CN}^{*}\right)$ is known to react with $\mathrm{C}-\mathrm{C}$ double bonds ${ }^{49-51}$ and arenes ${ }^{52}$ forming $\mathrm{C}-\mathrm{C}$ bonds.

To provide further experimental evidence for this hypothesis we exposed the sample to 180 Langmuir of acetonitrile with the ion gauge in the preparation chamber turned off and under these conditions no molecular attachments were detected on the surface (see Supporting Information $\mathrm{G}$ for further details).

To gain atomic understanding of the reaction, we ran DFT calculations for the adsorption of $\mathrm{CH}_{2} \mathrm{CN}^{\bullet}$ on $\mathrm{gr} / \mathrm{Ru}(0001)$. The results are summarized in Figure 4. In agreement with the experimental data, the adsorption energies are within the limits of a covalent bond $(>2.1 \mathrm{eV})(\mathrm{see}$ Figure 4(a)). Remarkably, the HCP-Top/FCC-Top preference we observe experimentally is also reproduced. The two most stable configurations, HCP-Top(1) and HCP-Top(4), with adsorption energies of $2.34 \mathrm{eV}$ and $2.49 \mathrm{eV}$ are shown in Fig. 4(c), and Fig. 4(d). In this case, it is the alkyl carbon atom of $\mathrm{CH}_{2} \mathrm{CN}^{\bullet}$ that lies closer to the graphene surface, as is observed in the cycanomethylation of arenes. ${ }^{52}$ The graphene carbon atom immediately below the $\mathrm{CH}_{2} \mathrm{CN}$ 
addend is clearly displaced from the graphene mesh (see Supporting Information F for details). The shortest distance between an acetonitrile carbon atom and a graphene atom are $1.60 \AA$ and $1.58 \AA$ for the acetonitrile in the HCP-Top (1) and HCP-Top(4) adsorption geometries shown in Fig. 4(c) and Fig. 4(d), in very good accordance with a C-C single bond, for which the textbook C-C distance is $1.54 \AA .^{53}$ Other configurations considered and the corresponding adsorption energies are shown in Table S1 and Figure S6 and discussion in section F.3 of the SI. In contrast, identical calculations run with $\mathrm{CH}_{3} \mathrm{CN}$ resulted in adsorption energies of $0.40 \pm 0.03 \mathrm{eV}$ and $0.42 \pm 0.02 \mathrm{eV}$ for the HCP-top and FCC-top regions, respectively, with the shortest acetonitrilegraphene distances $>3 \AA$, indicative of physisorption, as expected (see table S2 and Figure S8 in section F.3 of the SI). 


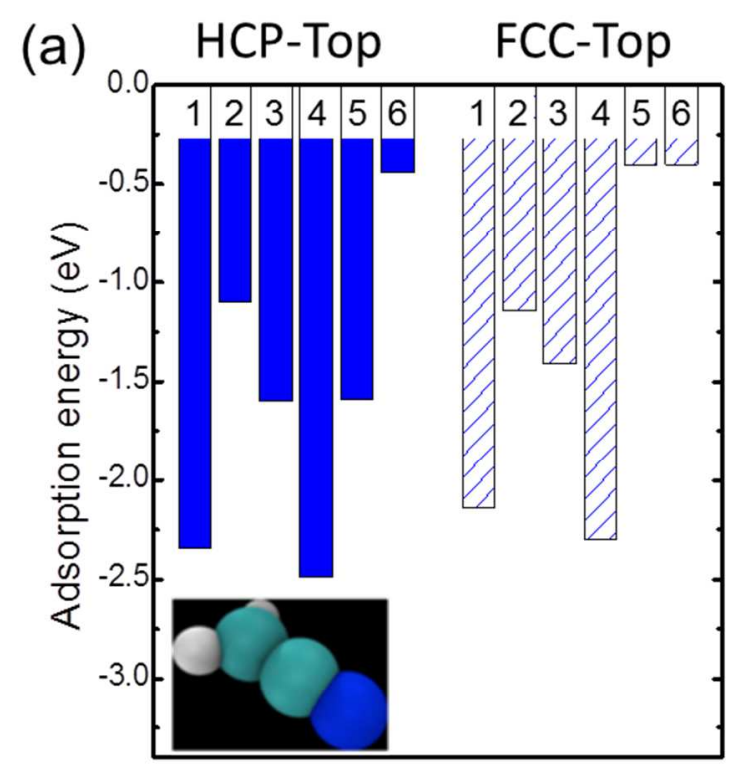

(b)

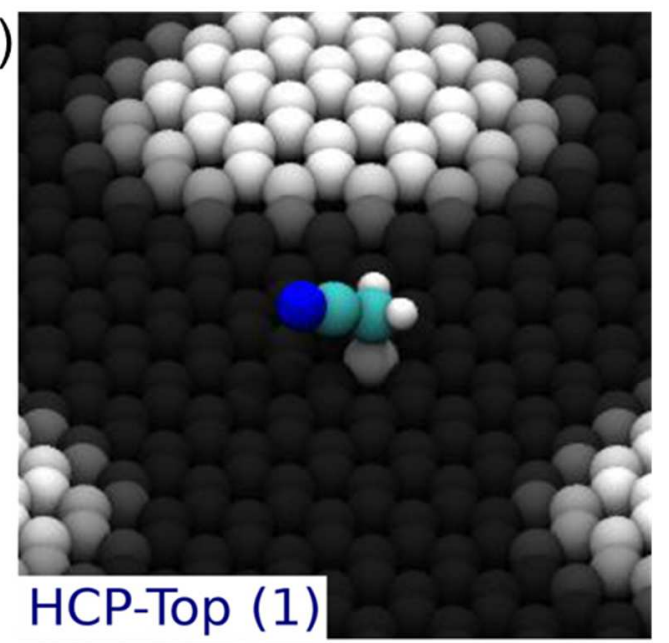

(c)

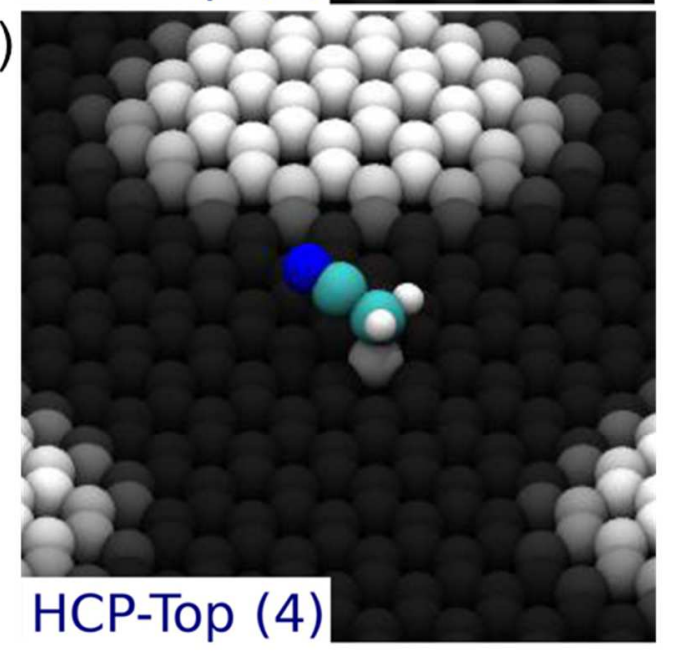


Figure 4. (a) Adsorption energies calculated for the different configurations of $\mathrm{CH}_{2} \mathrm{CN}^{*}$ on the HCP-top (solid boxes) and on the FCC-Top (empty boxes) regions of the gr/Ru(0001) moiré. The inset shows the ground state geometry of the corresponding molecule in the gas-phase. (b) and (c), Ground state adsorption geometries of the two most stable configurations of $\mathrm{CH} 2 \mathrm{CN}^{*}$ adsorbed in the HCP-Top region of the gr/Ru(0001) moiré. Graphene atoms are colored from dark-gray to white depending on their height. Carbon, nitrogen and hydrogen atoms of the molecule are colored in cyan, blue and white.

To investigate the role of the Ru metallic substrate we synthesised graphene on $\operatorname{Ir}(111)$ (hereafter, $\operatorname{gr} / \operatorname{Ir}(111)$ ), a system which exhibits a similar moiré pattern ${ }^{54}$ but with almost negligible charge transfer and interaction between the carbon and iridium. Exposing $\operatorname{gr} / \operatorname{Ir}(111)$ to $1 \times 10^{-6}$ Torr of $\mathrm{CH}_{3} \mathrm{CN}$, no $\mathrm{CH}_{2} \mathrm{CN}^{\bullet}$ attachments were observed, confirming that the strong interaction between $\mathrm{Ru}$ and the graphene overlayer plays a fundamental role in the covalent functionalization (see Supporting Information E for details).

Due to the strong interaction between graphene and the $\mathrm{Ru}(0001)$ surface, the moire pattern not only presents specific atomic sites with high chemical reactivity but long range order as well. In this system it is possible to grow graphene layers presenting lateral domain sizes exceeding 300 nm. ${ }^{39,55}$ The large domain size together with the exquisite spatial selectivity of our functionalization method ensures the long range order of the functionalized surface. Figure 5 shows a $66 \times 40 \mathrm{~nm}^{2} \mathrm{STM}$ image of the functionalized $\mathrm{gr} / \mathrm{Ru}(0001)$. In the image $50 \%$ of the moiré unit cells are occupied by one chemically bonded $-\mathrm{CH}_{2} \mathrm{CN}$ molecule. Of those $98.6 \%$ are bonded in the HCP-Top areas, while only $1.4 \%$ of the $-\mathrm{CH}_{2} \mathrm{CN}$ are bonded to the FCC-TOP areas. 


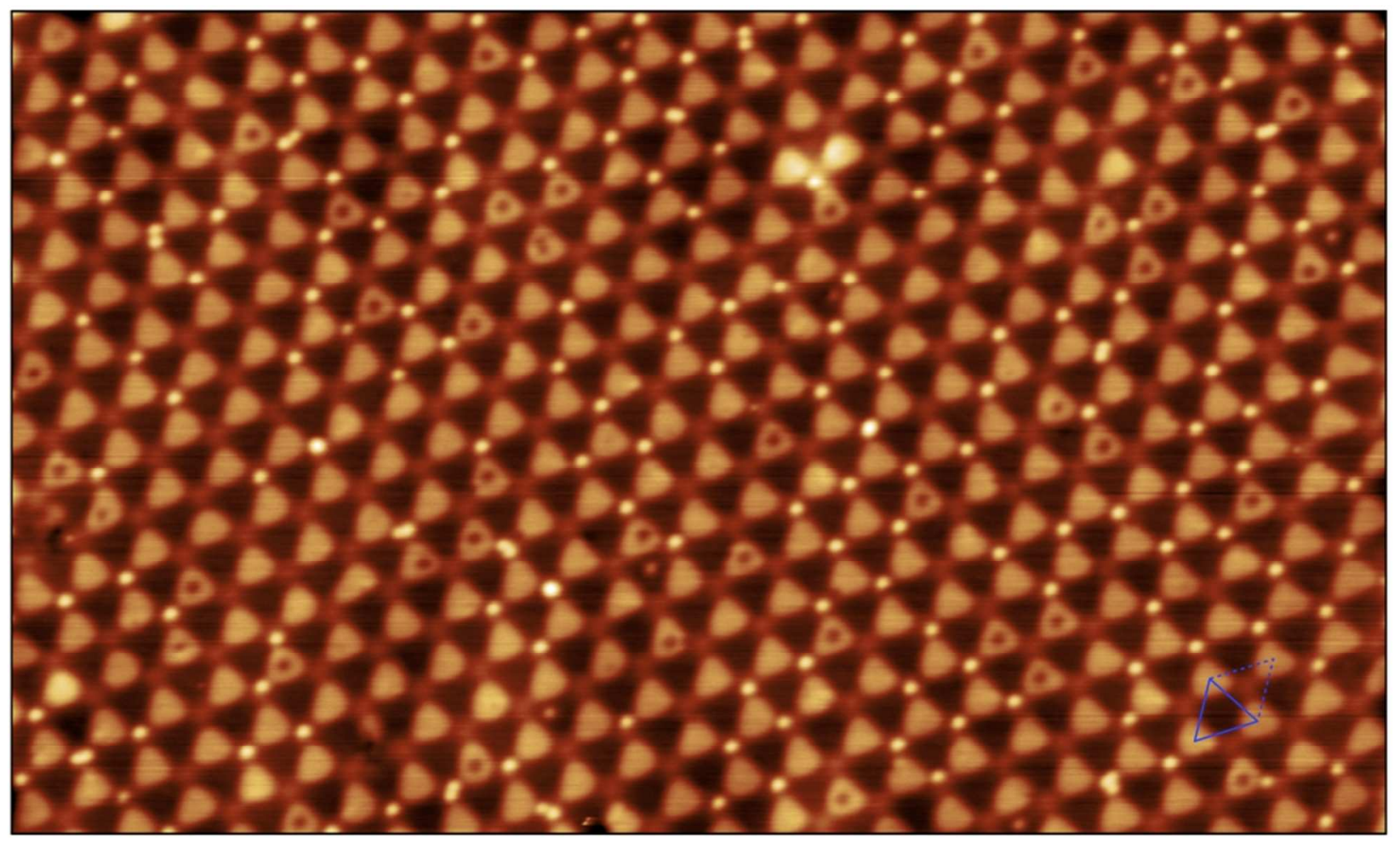

Figure 5. STM image $\left(66 \times 40 \mathrm{~nm}^{2}, \mathrm{~V}_{\mathrm{b}}=1.7 \mathrm{~V}, \mathrm{I}_{\mathrm{t}}=30 \mathrm{pA}\right)$ acquired at $80 \mathrm{~K}$ on a high coverage sample, prepared by exposing the $\mathrm{gr} / \mathrm{Ru}(0001)$ surface to 600 Langmuir of acetonitrile at $300 \mathrm{~K}$. The moiré unit cell is highlighted in blue.

Similar results have been obtained for propionitrile, isobutyronitrile and 2-phenylacetonitrile, demonstrating the applicability of this functionalization method to other molecular species (see Supporting Information $\mathrm{H}$ for details).

In conclusion, we take advantage of the nanostructuration induced on graphene grown on $\mathrm{Ru}(0001)$ to chemically functionalize the graphene overlayer with atomic-level selectivity and exquisite spatial periodicity. The comparison between graphene grown on $\operatorname{Ir}(111)$ and graphene on $\mathrm{Ru}(0001)$ shows the importance of the interaction between the graphene and the metallic substrate that spatially modulates the properties of the graphene. Acetonitrile is homolytically 
broken by electron bombardment producing cyanomethyl radicals that react with the nanostructured graphene in a spatially modulated fashion. These results offer the possibility for tuning the graphene electronic, optic or magnetic properties trough an adequate covalent functionalization of single layer graphene with long-range order on the order of hundreds of nanometers and a periodicity of almost $3 \mathrm{~nm}$. Moreover, identical results were obtained for propionitrile, isobutyronitrile and 2-phenylacetonitrile, establishing a benchmark for the attachment of more complex molecular structures to specific atomic sites on graphene.

\section{Methods.}

All experiments were performed in an UHV chamber with a base pressure of $5 \times 10^{-11}$ Torr equipped with a low-temperature STM and facilities for tip and sample preparation. All the STM measurements were carried out at $80 \mathrm{~K}$. The graphene layer was prepared by keeping the $\mathrm{Ru}$ crystal at $1150 \mathrm{~K}$ in UHV while exposing it to an ethylene partial pressure of $8 \times 10^{-8}$ Torr for 10 min. Acetonitrile was introduce in the UHV chamber via a leak valve to produce a partial pressure of $1 \times 10^{-6}$ Torr. The values for the partial pressures of the different gases are measured using a Bayard-Alpert gauge calibrated for $\mathrm{N}_{2}$. The details of the calculations are provided in the Supporting Information.

\section{ASSOCIATED CONTENT}

Supporting Information. Detailed discussion of the graphene/Ru(0001) structure. Oxygen contamination identification. Wet chemistry approach. Relative abundance of the cyanomethyl radical versus the acetonitrile molecule. Adsorption on graphene/ $\operatorname{Ir}(111)$. Theoretical calculations. Ion gauge influence on the functionalization. Functionalization with different 
molecules $\left(\mathrm{CH}_{3} \mathrm{CH}_{2} \mathrm{CN},\left(\mathrm{CH}_{3}\right)_{2} \mathrm{CHCN}\right.$ and $\left.\mathrm{Ph}-\mathrm{CH}_{2} \mathrm{CN}\right)$. This material is available free of charge via the Internet at http://pubs.acs.org."

\title{
AUTHOR INFORMATION
}

\section{Corresponding Author}

* (A.L.V.d.P.) al.vazquezdeparga@uam.es; (E.M.P.) emilio.perez@imdea.org

\section{Present Addresses}

$\uparrow$ Center for nanostructured Graphene, Department of Micro- and Nanotechnology, Technical University of Denmark, Ørsteds plads, Building 345B, DK-2800 Kgs., Lyngby, Denmark.

† Physik-Department E20, TU München, James-Franck str. 1, D-85748 Garching, Germany

\author{
Author Contributions \\ The experiments and data analysis were carried out primarily by F.C., J.J.N, with important \\ contributions by A.B., R.B.-G. and M.G. S.L. performed the wet chemistry experiments. D.S. \\ performed the theoretical calculations and contributed to the writing of the manuscript. D.G. \\ contributed with the data analysis and contributed to the writing to the manuscript. R.M. \\ contributed to the writing of the manuscript. E.M.P. and A.L.V.P. designed the experiments and \\ wrote the manuscript with contributions from all authors.
}

\section{Notes}

The results described here are partially protected under Spanish patent application P201530126.

\section{ACKNOWLEDGMENT}


Financial support by the European Research Council (MINT, ERC-StG- 2012-307609) the

Ministerio de Economía y Competitividad (MINECO) FIS2013-40667-P and CTQ2014-60541-

P, and Comunidad de Madrid through the programme MAD2D P2013/MIT-3007 and

Nanofrontmag S2013/MIT-2850 is gratefully acknowledged. D.G. acknowledges RyC-2012-

09864. R.B.-G. acknowledges BES-2011-050821.

\section{REFERENCES}

1. Geim, A. K.; Novoselov, K. S. Nature Mater. 2007, 6, 183-191.

2. Georgakilas, V.; Otypka, M.; Bourlinos, A.B.; Chandra, V.; Kim, N.; Kemp, K.C.; Hobza, P.; Zboril, R.; Kim, K.S. Chem. Rev. 2012, 112, 6156-6214.

3. Chua, C. K.; Pumera, M. Chem. Soc. Rev. 2013, 42, 3222-3233.

4. Park, J.; Yan, M. Acc. Chem. Res. 2013, 46, 181-189.

5. Kuila, T.; Bose, S.; Kumar, A.; Khanra, P.; Kim, N.H.; Lee, J.H. . Progress in Materials Science 2012, 57, 1061-1105.

6. Sun, Z.; James; D.K; Tour, J.M. J. Phys. Chem. Lett. 2011, 2, 2425-2432.

7. Criado, A.; Melchiona, M.; Marchesan, S.; Prato, M. Angew. Chem. Int. Ed. 2015, 54, 1073410750.

8. Criado, A.; Melchiona, M.; Marchesan, S.; Prato, M. Angew. Chem. Int. Ed. 2015, 54, 2-19.

9. Schedin, F.; Geim, A.K.; Morozov, S.V.; Hill, E.W.; Blake, P.; Katsnelson, M.I.; Novoselov, K.S. Nature Mater. 2007, 6, 652-655. 
10. Garnica, M.; Stradi, D.; Barja, S.; Calleja, F.; Díaz, C.; Alcamí, M.; Vázquez de Parga, A.L.; Martín, F.; Miranda, R. Nature Phys. 2013, 9, 368-374.

11. Vinogradov, N.A.; Schulte, K.; Ng, M.L.; Mikkelsen, A.; Lundgren, E.; Mårtensson, N.; Preobrajenski, A.B. J. Phys. Chem. C 2011, 115, 9568-9577.

12. Hossain, M.Z.; Johns, J.E.; Bevan, K.H.; Kamel, H.J.; Liang, Y.T.; Yoshimoto, S.; Mukai, K.; Koitaya, T.; Yoshinobu, J.; Kawai, M.; Lear, A.M.; Kesmodel, L.L.; Tait, S.L.; Hersam, M.C. Nature Chem. 2012, 4, 305-309.

13. Sofo, J.O.; Chaudhari, A.S.; Barber, G.D. Phys. Rev. B 2007, 75, 153401.

14. Boukhvalov, D.W.; Katsnelson, M.I.; Lichtenstein, A.I. Phys. Rev. B 2008, 77, 035427.

15. Elias, D. C.; Nair, R.R.; Mohiuddin, T.M.G.; Morozov, S.V.; Blake, P.; Halsall, M.P.; Ferrari, A.C.; Boukhvalov, D.W.; Katsnelson, M.I.; Geim, A.K.; Novoselov, K.S. Science 2008, $323,610-613$.

16. Haberer, D.; Vyalikh, D.V.; Taioli, S.; Dora, B.; Farjam, M.; Fink, J.; Marchenko, D.;

Pichler, T.; Ziegler, K.; Simonucci, S.; Dresselhaus, M.S.; Knupfer, M.; Büchner, B.; Grüneis, A. Nano Lett. 2010, 10, 3360-3366.

17. Park, C.H.; Yang, L.; Son, Y.W.; Cohen, M.L; Louie, S.G. Nature Phys. 2008, 4, 213-217.

18. Ouyang, F.; Peng, S.; Liu, Z.; Liu, Z. ACS Nano 2011, 5, 4023-4030.

19. Dvorak, M.; Oswald, W.; Wu, Z. Sci. Rep. 2013, 3, 2289. 
20. Bian, S.; Scott, A.M.; Cao, Y.; Liang, Y.; Osuna, S.; Houk, K.N.; Braunschweig, A.B. J. Am. Chem. Soc. 2013, 135, 9240-9243.

21. Hossain, M.Z.; Walsh, M.A.; Hersam, M.C. J. Am. Chem. Soc. 2010, 132, 15399-15403.

22. Wu, Q.; Wu, Y.; Hao, Y.; Geng, J.; Charlton, M.; Chen, S.; Ren, Y.; Ji, H.; Li, H.;

Boukhvalov, D.W.; Piner, R.D.; Bielawski, C.W.; Ruoff, R.S. Chem. Commun. 2013, 49, 677679.

23. Bissett, M. A.; Konabe, S.; Okada, S.; Tsuji, M.; Ago, H. ACS Nano 2013, 7, 10335-10343.

24. Vázquez de Parga, A.L.; Miranda, R. In Graphene:Properties, preparation, characterisation and devices; Chap 6; Skakalova, V., Kaiser, A.B., Eds.; Woodhead Publising, (2014).

25. Balog, R.; Jørgensen, B.; Nilsson, L.; Andersen, M.; Rienks, E.; Bianchi, M.; Fanetti, M.; Laegsgaard, E.; Baraldi, A.; Lizzit, S.; Sljivancanin, Z.; Besenbacher, F.; Hammer, B.; Pedersen, T.G.; Hofmann, P.; Hornekaer, L. Nature Mater. 2010, 9, 315-319.

26. Balog, R.; Andersen, M.; Jørgensen, B.; Slijvancanin, Z.; Hammer, B.; Baraldi, A.; Larciprete, R.; Hofmann, P.; Hornekaer, L.; Lizzit, S., ACS Nano 2013, 7, 3823-3832.

27. Coraux, J; N’Diaye, A.T.N.; Buss, C.; Michely, T. Nano Lett. 2008, 8, 565-570.

28. Loginova, E.; Nie, S.; Thumer, K.; Bartelt, N.C.; McCarty, K.F. Phys. Rev. B 2009, 80, 085430.

29. Chae, S. J.Günes, F.; Kim, K.K.; Kim, E.S.; Han, G.H.; Kim, S.M.; Shin, H.J.; Yoon, S.M., Choi, J.Y.; Park, M.H.; Yang, C.W.; Pribat, D.; Lee, Y.H. Adv. Mater. 2009, 21, 2328-2333. 
30. Reina, A.; Jia, X.; Ho, J.; Nezich, D.; Son, H.; Bulovic, V.; Dresselhaus, M.S.; Kong, J. Nano Lett. 2009, 9, 30-35.

31. Li, X.; Cai, X.; An, J.; Kim, S.; Nah, J.; Yang, D.; Piner, R.; Velamakanni, A.; Jung, I.;

Tutuc, E.; Banerjee, S.K.; Colombo, L.; Ruoff, R.S. Science 2009, 324, 1312-1314.

32. Lee, Y.; Bae, S.; Jang, H.; Jang, S.; Zhu, S.E.; Sim, S.H.; Song, Y.I.; Hong, B.H.; Ahn, J.H. Nano Lett. 2010, 10, 490-493.

33. Preobrajenski, A.B.; Ng, M.L.; Vinogradov, A.S.; Martensson, N. Phys. Rev. B 2008, 78, 073401.

34. Vazquez de Parga, A. L.; Calleja, F.; Borca, B.; Hinarejos, J.J.; Passeggi, M.G.C.; Guinea, F.; Miranda, R.. Phys. Rev. Lett. 2008, 100, 056807.

35. Stradi, D.; Barja, S.; Díaz, C.; Garnica, M.; Borca, B.; Hinarejos, J.J.; Sánchez-Portal, D.; Alcamí, M.; Arnau, A.; Vázquez de Parga, A.L.; Miranda, R.; Martín, F. Phys. Rev. B 2013, 88, 245401 .

36. Stradi, D.; Barja, S.; Díaz, C.; Garnica, M.; Borca, B.; Hinarejos, J.J.; Sánchez-Portal, D.; Alcamí, M.; Arnau,A.; Vázquez de Parga, A.L.; Miranda, R.; Martín, F. Phys. Rev. Lett. 2011, $106,186102$.

37. Borca, B.; Barja, S.; Garnica, M.; Sánchez-Portal, D.; Silkin, V.M.; Chulkov, E.V.;

Hermanns, C.F.; Hinarejos, J.J.; Vázquez de Parga, A.L.; Arnau, A.; Echenique, P.M.; Miranda, R. Phys. Rev. Lett. 2010, 105, 036804.

38. Katano, S.; Kim, Y.; Trenary, M.; Kawai, M. Chem. Commun. 2013, 49, 4679-4681. 
39. Borca, B.; Barja, S.; Garnica, M.; Minniti, M.; Politano, A.; Rodríguez-García, J.M.;

Hinarejos, J.J., Farías, D.; Vázquez de Parga, A.L.; Miranda, R. New J. Phys. 2010, 12, 093018.

40. Garnica, M.; Stradi, D.; Calleja, F.; Barja, S.; Díaz, C.; Alcamí, M.; Arnau, A.; Vázquez de Parga, A.L.; Martín, F.; Miranda, R. Nano Lett. 2014, 4, 4560-4567.

41. Stradi, D.; Garnica, M.; Díaz, C.; Calleja, F.; Barja, S.; Alcamí, M.; Martín, N.; Arnau, A.;

Vázquez de Parga, A.L.; Miranda, R.; Martín, F. Nanoscale 2014, 6, 15271-15279.

42. Barja, S., Garnica, M.; Hinarejos, J.J.; Vázquez de Parga, A.L.; Martín, N.; Miranda, R., Chem. Comm. 2010, 46, 8198-8200.

43. Stroscio, J. A.; Eigler, D. M. Science 1991, 254, 1319-1326.

44. Hla, S.-W. J. Vac. Sci. Technol., B 2005, 23, 1351-1360.

45. Caillier, C.; Ki, D.K.; Lisunova, Y.; Gaponenko, I.; Paruch, P.; Morpugo, A.F. Nanotechnology 2013, 24, 405201.

46. Lalevee, J.; Allonas, X.;Fouassier, J.-P. J. Org. Chem. 2005, 70, 814-819.

47. Henry, D.J.; Parkinson, C.J.; Mayer, P.M.; Radom, L. J. Phys. Chem. A 2001, 105, 67506756.

48. Coote, M.L. J. Phys. Chem. A 2004, 108, 3865-3872.

49. Kukk, E.; Sankari, R.; Huttula, M.; Sankari, A.; Aksela, H.; Aksela, S. J. Electron Spectrosc. Relat. Phenom. 2007, 155, 141-147.

50. Wu, J. Q.; Beranek, I.; Fischer, H. Helv. Chim. Acta 1995, 78, 194-214. 
51. Wong, M. W.; Radom, L. J. Phys. Chem. 1995, 99, 8582-8588.

52. Yoshida, H.; Fujimura, Y.; Yuzawa, H.; Kumagai, J.; Yoshida, T. Chem. Commun. 2013, 49, 3793-3795.

53. Cottrell, T. L. The Strengths of Chemical Bonds. Butterworth Scientific (1978)

54. N'Diaye, A.T.; Coraux, J.; Plasa, T.N.; Busse, C.; Michely, T. New J. Phys. 2008, 10, 043033.

55. Sutter, P.W.; Flege, J.I.; Sutter, E.A. Nature Mater. 2008, 7, 406-500. 
TOC graphics

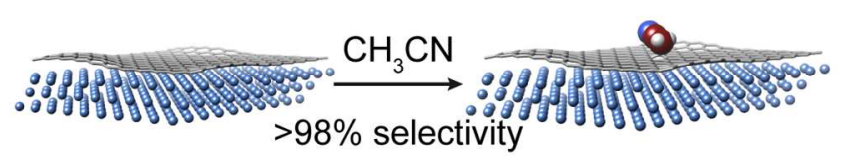




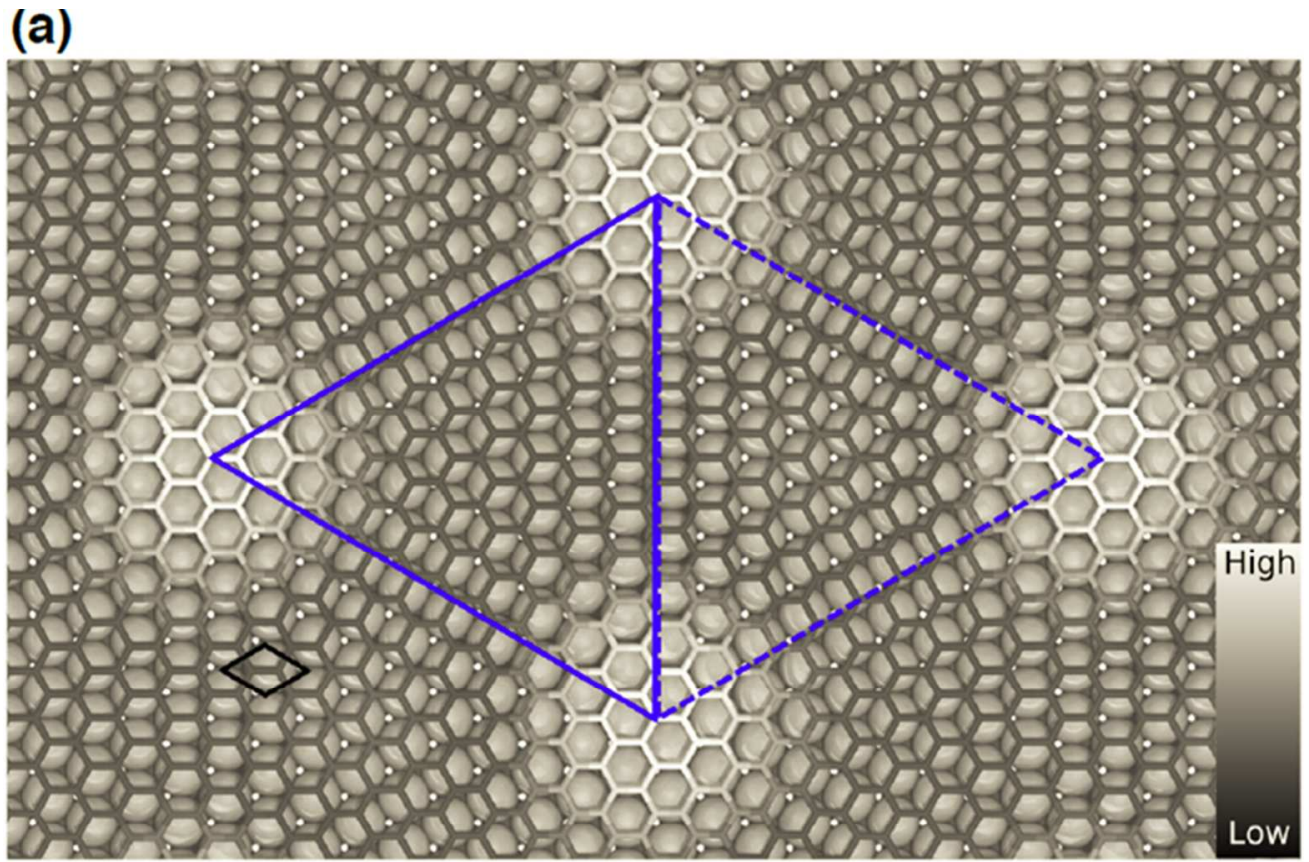

(b)

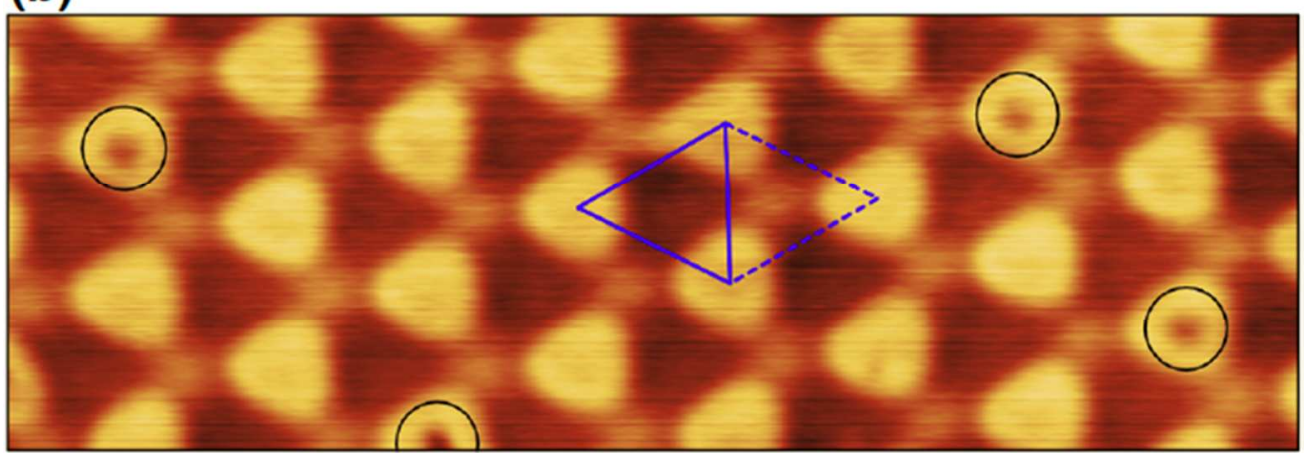

Figure 1. (a) Ball model of the gr/Ru(0001) surface, where grey circles represent the Ru atoms of the first atomic layer. The graphene hexagonal lattice is shown in a black to white color scale to indicate the height of the carbon atoms respect to the Ru(0001) surface. The unit cell of the moiré pattern is highlighted by two blue triangles. At the vertices all carbon atoms fall on threefold hollow sites of the $\mathrm{Ru}(0001)$ surface. At the center of the solid (dashed) triangle one carbon sub-lattice falls on FCC-stacked (HCP-stacked) threefold hollow sites and the other one on top positions. These two regions are named "FCC-Top" and "HCP-Top" respectively. (b) STM image acquired on pristine gr/Ru(0001) $\left(24 \times 7 \mathrm{~nm}^{2} ; \mathrm{V}_{\mathrm{b}}=+1.5 \mathrm{~V}, \mathrm{I}_{\mathrm{t}}=30 \mathrm{pA}\right)$. The moiré pattern arising from the lattice mismatch is highlighted in blue. The HCP-Top area is marked with the dashed triangle and the FCC-Top area is marked the solid triangle. Four point defects on the atop areas are indicated by black circles. $189 \times 195 \mathrm{~mm}$ (103 x 104 DPI) 

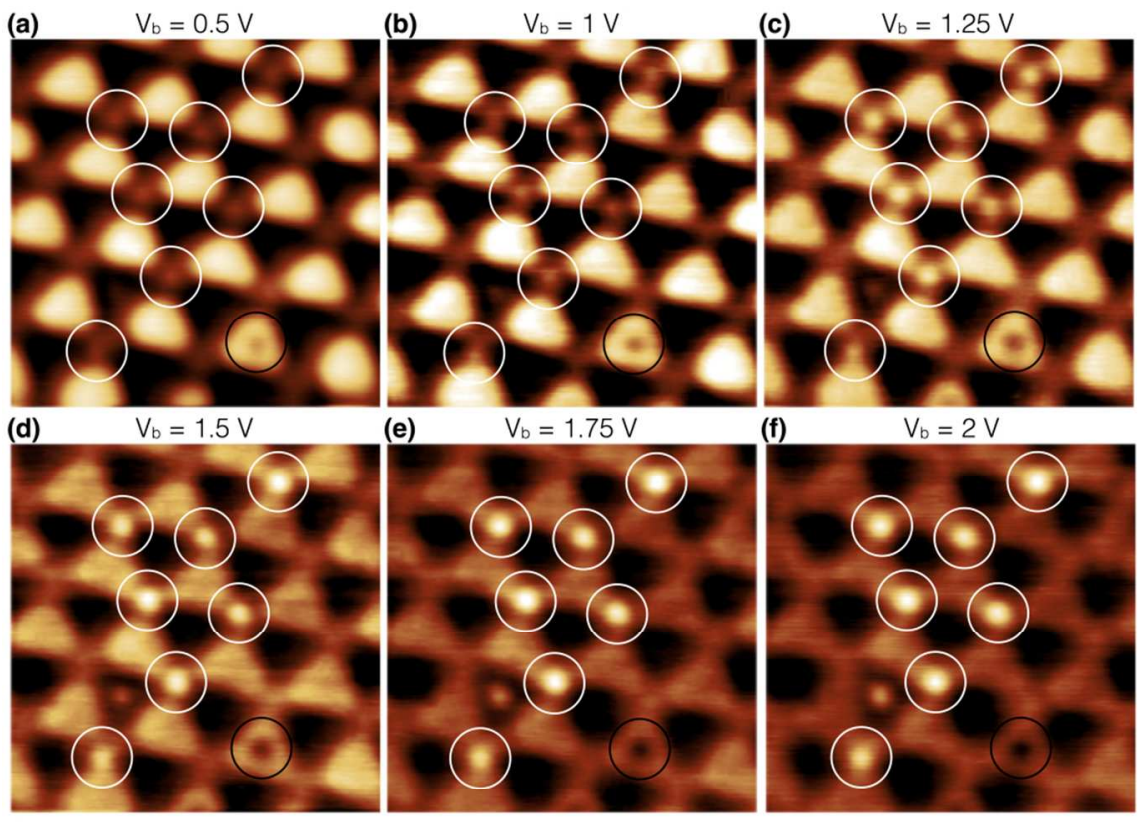

(g)

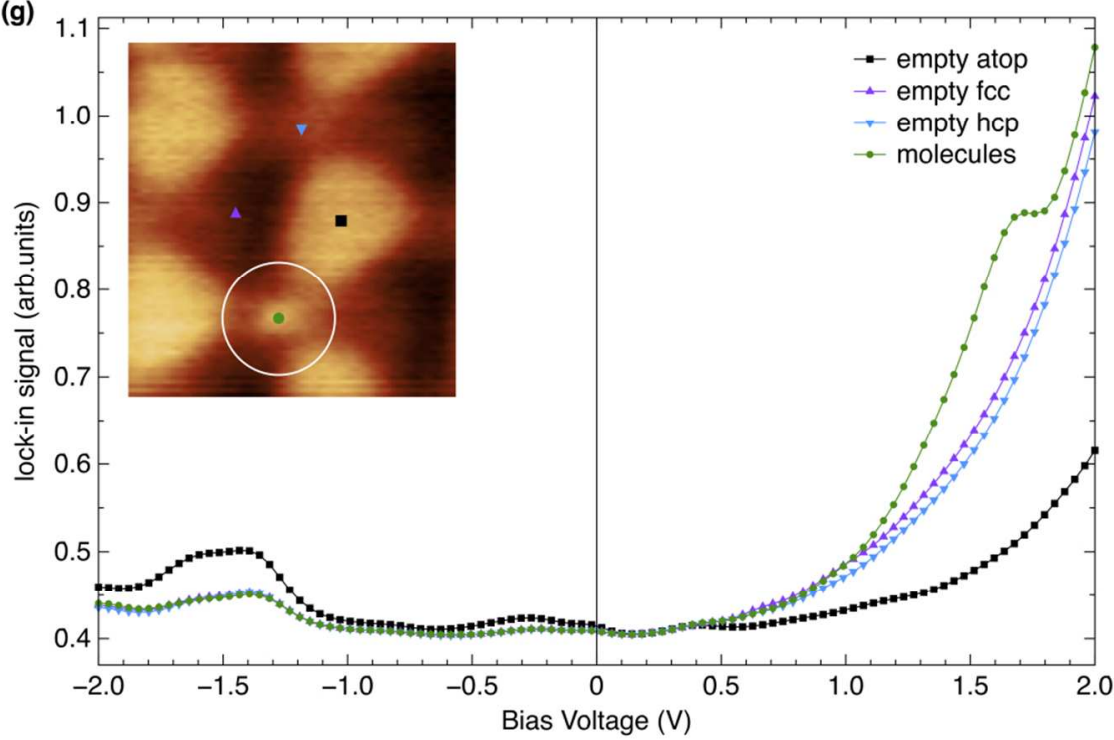

Figure 2. (a)-(f) $10 \times 10 \mathrm{~nm}^{2}$ STM images with different bias voltages acquired at $80 \mathrm{~K}$ after exposing $\mathrm{gr} / \mathrm{Ru}(0001)$ to 180 Langmuir of acetonitrile at $300 \mathrm{~K}$. Notice the related presence of seven bright bumps on HCP-Top sites (marked with a white circle), one on FCC-Top site and one graphene point defect (marked with a black circle). (g) Differential conductance, dI/dV, curves recorded at $80 \mathrm{~K}$ with the tip of the STM placed on top of the molecular attachments (green), the FCC-Top, HCP-Top (purple and blue, respectively)

and the ripples (black) areas of the moiré pattern of $\mathrm{gr} / \mathrm{Ru}(0001)$. The $\mathrm{dI} / \mathrm{dV}$ individual curves were measured in open feedback loop conditions with the tunneling gap stabilized at $+0.3 \mathrm{~V}$ and $50 \mathrm{pA}$. The lock-in signal was acquired using a modulation in the bias voltage of $40 \mathrm{mV}(\mathrm{rms})$, a frequency of $856 \mathrm{~Hz}$ and a time constant of $10 \mathrm{~ms}$.

$152 \times 208 \mathrm{~mm}(171 \times 171$ DPI $)$ 
Figure 3. High resolution STM image $\left(17 \times 12 \mathrm{~nm}^{2}, \mathrm{~V}_{\mathrm{b}}=2 \mathrm{mV}, \mathrm{I}_{\mathrm{t}}=800 \mathrm{pA}\right)$, acquired at $80 \mathrm{~K}$ on a region containing three molecular species (white circles) and two oxygen-related defects on graphene (black circles). Inset: Same region scanned afterwards with $\mathrm{V}_{\mathrm{b}}=+1.7 \mathrm{~V}$ and $\mathrm{I}_{\mathrm{t}}=100 \mathrm{pA}$. All three molecular attachments are still in place. The moiré unit cell is highlighted in blue in the inset. $180 \times 122 \mathrm{~mm}(138 \times 138 \mathrm{DPI})$ 


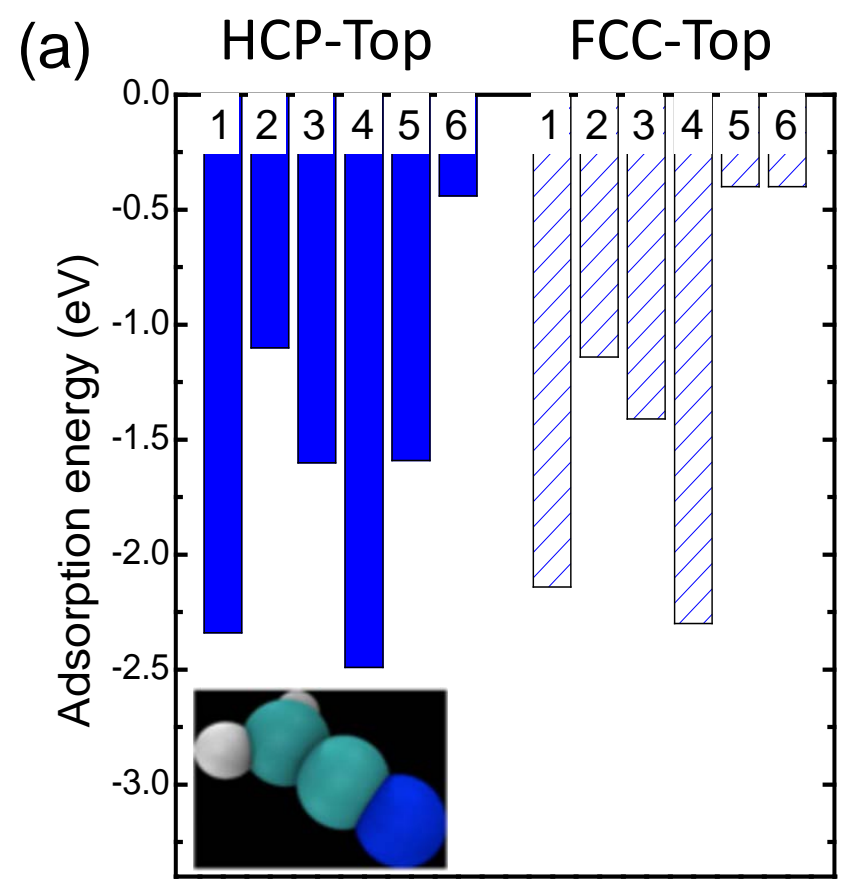

(b)

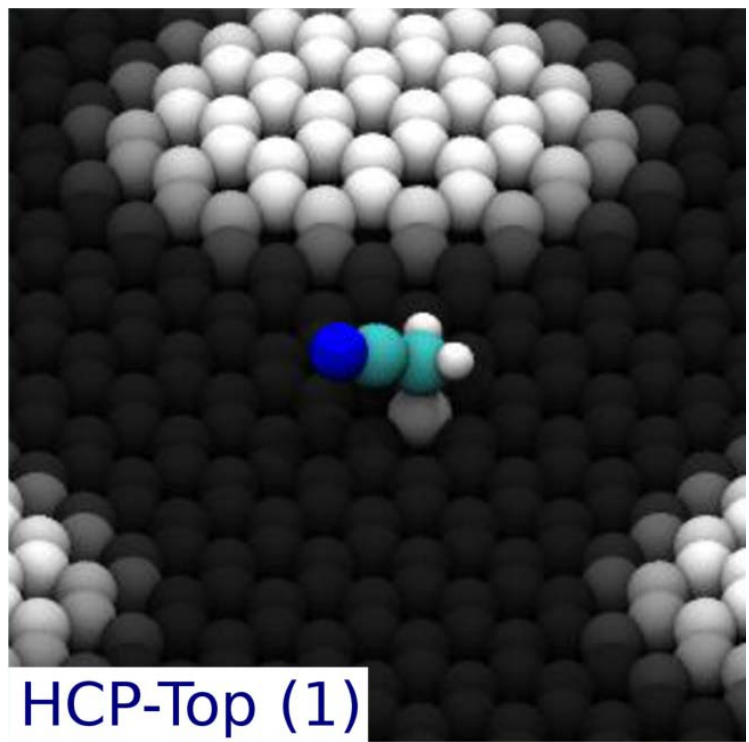

(c)

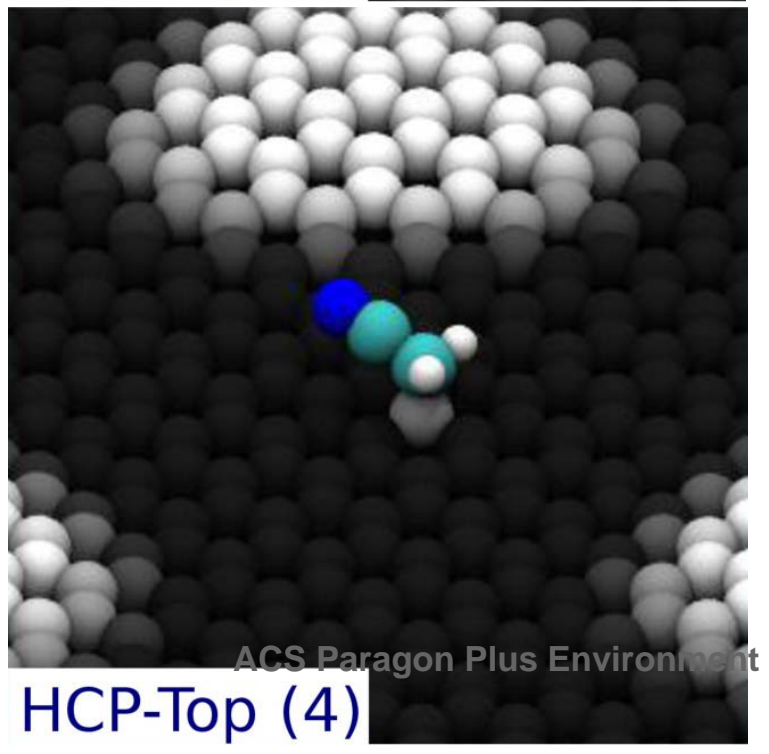


Figure 5. STM image $\left(66 \times 40 \mathrm{~nm}^{2}, \mathrm{~V}_{\mathrm{b}}=1.7 \mathrm{~V}, \mathrm{I}_{\mathrm{t}}=30 \mathrm{pA}\right)$ acquired at $80 \mathrm{~K}$ on a high coverage sample, prepared by exposing the $\mathrm{gr} / \mathrm{Ru}(0001)$ surface to 600 Langmuir of acetonitrile at $300 \mathrm{~K}$. The moiré unit cell is highlighted in blue. $180 \times 108 \mathrm{~mm}(144 \times 144$ DPI) 